\title{
Queen acceptance in a socially polymorphic ant
}

\author{
Joël Meunier*, Anabelle Reber ${ }^{1}$, Michel Chapuisat ${ }^{1}$ \\ Department of Ecology and Evolution, Biophore, University of Lausanne
}

\section{A R T I C L E I N F O}

\section{Article history:}

Received 31 May 2010

Initial acceptance 16 July 2010

Final acceptance 22 September 2010

Available online 30 October 2010

MS. number: 10-00387R

\section{Keywords:}

Formica selysi

nestmate recognition

queen number

social evolution

The evolution of cooperative social groups in which a few members monopolize reproduction constitutes one of the major evolutionary transitions of life on earth (Szathmary \& Maynard Smith 1995). Cooperative breeding occurs in a great variety of taxa, from arthropods to birds and mammals (Jennions \& Macdonald 1994; Sherman et al. 1995). In many cooperatively breeding vertebrates, offspring postpone dispersal and reproduction to help their parents, while retaining the possibility of delayed breeding (Emlen 1997). In the eusocial insects, the reproductive specialization is more pronounced and generally permanent: queens and males perform most of the reproduction, while workers undertake nonreproductive tasks such as foraging or colony defence (Wilson 1971).

In bees, wasps and ants, eusociality primarily evolved by kin selection in ancestral lineages where the colonies were headed by one single-mated queen (Hughes et al. 2008a, b). Secondarily, there have been multiple transitions towards polygyny: the simultaneous presence of multiple reproductive queens in the same colony (Hölldobler \& Wilson 1990; Hughes et al. 2008a). Polygyny is

\footnotetext{
* Correspondence and present address: J. Meunier, Zoological Institute, Evolutionary Biology, University of Basel, Vesalgasse 1, 4051 Basel, Switzerland. E-mail address: joel.meunier@unibas.ch (J. Meunier).

1 A. Reber and M. Chapuisat are at the Department of Ecology and Evolution, Biophore, University of Lausanne, 1015 Lausanne, Switzerland.
}

particularly common in ants, where it occurs in more than $40 \%$ of the species (Hughes et al. 2008b).

The evolution and maintenance of multiple-queen colonies seems paradoxical at first, as it decreases the relatedness among colony members and consequently the inclusive fitness of workers (Hamilton 1964). However, shifts from single-queen (monogyne) to multiple-queen (polygyne) colonies are generally associated with profound changes in dispersal and life histories (Bourke \& Franks 1995; Rosset \& Chapuisat 2007). Polygyny might thus be favoured under some ecological conditions, particularly when independent colony founding by queens becomes difficult (Keller 1995).

Identifying the proximate and ultimate factors that influence the number of breeders per social group has become a central question in studies of social evolution. The number of breeders and apportionment of reproduction among breeders generally depends on ecological constraints limiting independent breeding, on the benefits of cooperation and on the power of each group member in determining the group dynamics (Keller \& Reeve 1994).

In ants, workers can regulate the number of queens per colony by eliminating or accepting young newly mated queens (alates) seeking adoption into their nest. Hence, the behavioural response of workers towards new queens may play a major role in determining colony social structure. On the one hand, if workers eliminate any mated queen trying to join the colony, this would provide a strong proximate mechanism contributing to maintaining a monogyne social structure. Such a process has been documented in two ant species, Formica argentea and the monogyne social form 
of the fire ant Solenopsis invicta (Bennett 1988; Ross \& Keller 1998). On the other hand, if workers accept additional queens, colonies will become or remain polygyne. In several ant species, monogyne colonies indeed accepted additional queens, which resulted in a shift towards polygyny (Evans 1996a; Souza et al. 2005; Hora et al. 2008; Zinck et al. 2009). The reaction of resident workers may also depend on the mating status of the queens seeking adoption into the colony. In two species of ants belonging to the genus Formica, workers were less tolerant towards mated queens than virgin queens, perhaps because of a change in odour cues or queen behaviour after mating (Sundström 1997; Holzer et al. 2008b).

The acceptance of additional queens alters the kin structure of the colony and generally decreases the relatedness of workers to brood. However, it may still be promoted by kin selection if workers accept additional queens produced by their colony (i.e. related queens) and reject unrelated queens produced by foreign colonies (Nonacs 1988; Pamilo 1991). In many polygyne ant species, workers are indeed more tolerant towards additional nestmate queens than towards foreign queens (Stuart et al. 1993; Evans 1996b; Kikuchi et al. 2007; Vasquez \& Silverman 2008; Cournault \& de Biseau 2009). Moreover, the relatedness among queens established in polygyne colonies is generally similar to the relatedness among nestmate workers, as expected if colonies recruit daughter queens (Crozier \& Pamilo 1996; Chapuisat \& Keller 1999). However, genetic data also reveal that unrelated queens can occasionally join existing colonies (Heinze \& Keller 2000; Holzer et al. 2009), and in some cases workers seem to accept unrelated, non-nestmate queens readily (Rosengren et al. 1986; Sundström 1997; Ross \& Keller 1998; Souza et al. 2005; Holzer et al. 2008a; Zinck et al. 2009).

Some species are socially polymorphic, in the sense that they have monogyne and polygyne colonies, sometimes in the same population (Deslippe \& Savolainen 1995; Chapuisat et al. 2004; Bargum et al. 2007). Such species provide the opportunity to test whether differences in the behaviour of workers from monogyne and polygyne colonies towards queens is a proximate mechanism contributing to the maintenance of this intraspecific social polymorphism. Workers from polygyne colonies might be more tolerant of additional queens for several reasons. Proximately, the presence of multiple resident queens is likely to result in a broader mix of genetically determined chemical cues that characterize the colony odour, which may decrease workers' ability to discriminate against non-nestmate conspecifics entering the colony (odour diversity hypothesis, see Hölldobler \& Wilson 1977; Breed \& Bennett 1987; Vander Meer \& Morel 1998). However, in some socially polymorphic species, workers from monogyne and polygyne colonies have a similar ability to discriminate non-nestmate workers (Rosset et al. 2007). Ultimately, the cost of accepting additional queens decreases once colonies have two or more resident queens, so that workers from monogyne colonies should be more reluctant to accept additional queens than workers from polygyne colonies (Pamilo 1991; reviewed in Bourke \& Franks 1995; Sundström 1997; Ross \& Keller 1998).

So far, studies of queen acceptance in socially polymorphic species have been mostly conducted in species such a S. invicta and Formica truncorum (Sundström 1997; Ross \& Keller 2002). In these species, the social forms generally occur in distinct populations and show large differences in their ecology and social organization (Ross \& Keller 1995). In S. invicta the pattern of queen acceptance depends on an interaction between the social origin of queens entering the colony and recipient workers. A single genetic element marked by an allelic polymorphism at the gene $G p-9$ influences the queen phenotype and the behaviour of workers. As a result, workers from monogyne colonies reject additional queens, while workers from polygyne colonies accept additional queens if these queens come from nestmate or non-nestmate polygyne colonies (Ross \& Keller 1998, 2002).
Surprisingly, few studies have investigated queen acceptance by workers in populations containing both monogyne and polygyne colonies. In Acromyrmex subterraneus molestans (Souza et al. 2005) and Ectatomma tuberculatum (Zinck et al. 2009), workers from monogyne colonies occasionally accepted additional foreign queens, but the behaviour of workers from polygyne colonies has not been investigated. In Myrmica tahoensis, a low proportion of non-nestmate mature queens were accepted by laboratory colonies; there was no significant effect of the social structure of the host colony, but the sample size was low (Evans 1996b). Hence, more data on the behaviour of resident workers towards young newly mated queens seeking adoption in their colony are needed to understand better the proximate mechanisms contributing to maintaining social structure variation in ants.

We studied queen acceptance by workers in a population of Formica selysi that contains monogyne and polygyne colonies in close proximity within the same habitat (Chapuisat et al. 2004). In this population, there is no sign of genetic differentiation at neutral markers between social forms (Chapuisat et al. 2004). Hence, some gene flow between monogyne and polygyne colonies is expected, and might be caused by (1) mating between queens and males of the alternative social origin (Reber et al. 2010), (2) founding of new monogyne or polygyne colonies by queens of the alternative social origin (Reber et al. 2010) and (3) new queens being accepted in colonies of the alternative social structure.

To investigate queen adoption in realistic conditions, we developed a bioassay involving freshly collected workers and young newly mated queens. In a full-factorial experiment, we explored the effects of the social origin of the recipient workers (monogyne or polygyne), social origin (nestmate, foreign monogyne or foreign polygyne) and mating status of the introduced queens on the rate of acceptance of additional queens by workers. This experiment allowed us to investigate whether the behaviour of resident workers towards new queens plays a role in maintaining colony integrity and social structure. In particular we examined: (1) whether workers are less tolerant towards foreign queens than towards nestmate queens, as expected if worker discrimination has been shaped by kin selection to prevent the exploitation of colony resources by unrelated individuals; (2) whether workers originating from polygyne colonies are more tolerant towards additional queens than workers originating from monogyne colonies, which is one of the potential proximate mechanisms that may contribute to maintaining social structure variation in insects; and (3) whether queen adoption leads to shifts in colony social structure and gene flow between social forms.

\section{METHODS}

Queens, males and workers came from a population of $F$. selysi located between Sierre and Susten along the River Rhône in central Valais, Switzerland $\left(7^{\circ} 36^{\prime} 30^{\prime \prime} \mathrm{E}, 46^{\circ} 18^{\prime} 30^{\prime \prime} \mathrm{N}\right.$, altitude $\left.565 \mathrm{~m}\right)$. The social structure (monogyne or polygyne) of each colony used in this experiment had been previously determined by genotyping 8-100 workers per colony at nine microsatellite markers (see Chapuisat et al. 2004; Reber et al. 2008).

Young virgin queens, males and workers were sampled from 13 monogyne and eight polygyne field colonies during the second week of June 2008. Queens and males from each field colony were kept in separate laboratory colonies to prevent uncontrolled mating until the experimental mating took place (see below). Each laboratory colony contained nestmate workers, brood (eggs, larvae and young pupae) and ground material from the original field colony, in a large plastic box $(35 \times 22 \mathrm{~cm}$ and $15 \mathrm{~cm})$ lined with fluon and covered by a net. The laboratory colonies were kept at $22 \pm 2{ }^{\circ} \mathrm{C}$ under a 16:8 h light:dark cycle. 


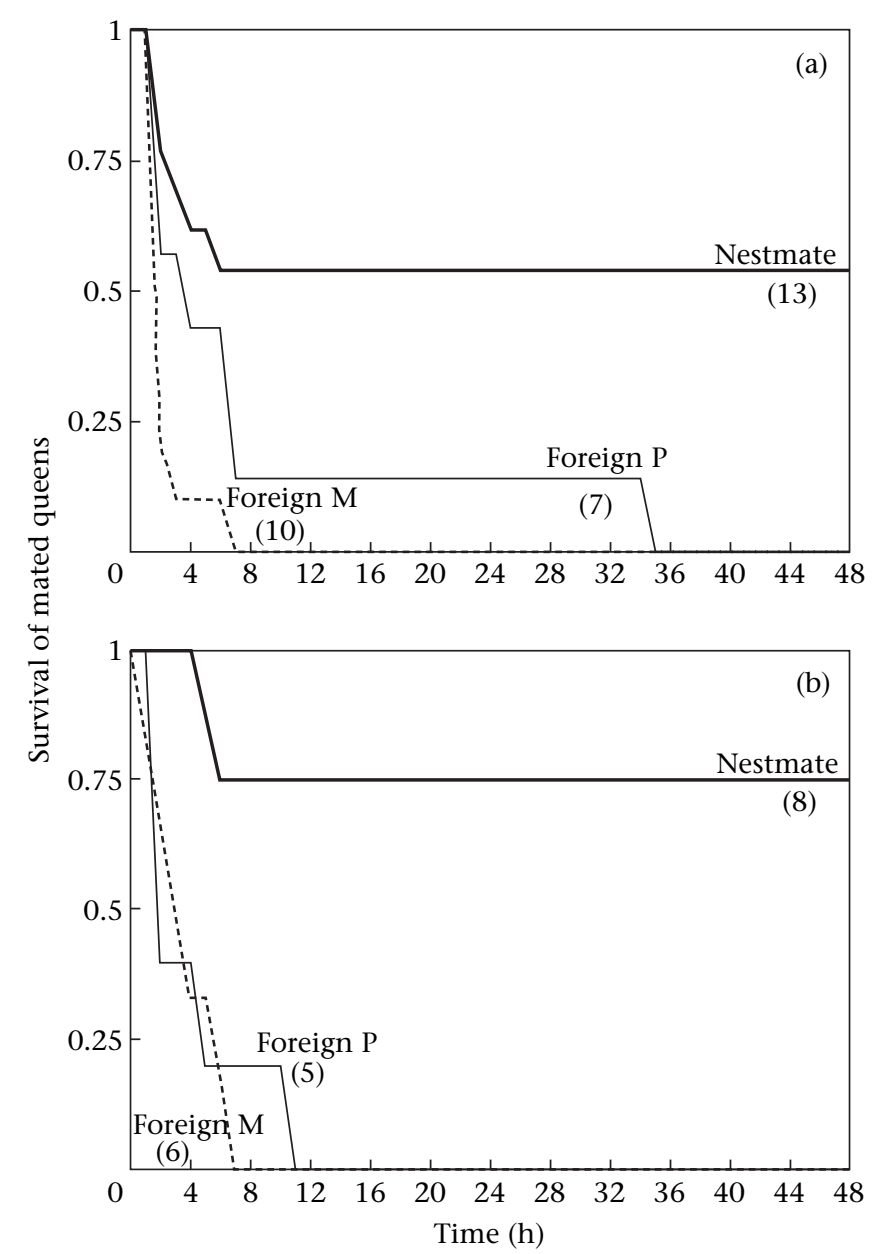

Figure 1. Cumulative survival of mated queens introduced into groups of workers originating from (a) monogyne colonies or (b) polygyne colonies. Queens came from nestmate colonies (Nestmate), non-nestmate monogyne colonies (Foreign $\mathrm{M}$ ) or non-nestmate polygyne colonies (Foreign $\mathrm{P}$ ). The number of recipient colonies is indicated in parentheses.

Experimental mating took place in the last week of June 2008 as described in Reber et al. (2010). We placed two virgin queens originating from the same colony with six unrelated males (three from monogyne colonies and three from polygyne colonies) in a large plastic box $(35 \times 22 \mathrm{~cm}$ and $15 \mathrm{~cm})$ covered with a net. The mating behaviour was monitored individually to ensure that mated queens were successfully inseminated (450 out of 454 queens mated using this method had full spermatheca, Reber et al. 2010). At the end of each mating, the queens were isolated in glass tubes containing humid cotton wool until they were reintroduced into recipient groups of workers.

The newly mated or virgin queens were introduced into groups of workers that had been freshly collected from the field. To minimize the influence that orphaning and captivity may have on the behaviour of workers, we collected the recipient workers from their field colonies in the morning, and the reintroduction of queens took place in the afternoon of the same day, less than $6 \mathrm{~h}$ after collection. A similar procedure has revealed variation in the discrimination behaviour of workers from monogyne and polygyne colonies towards eggs (Meunier et al. 2010). The queen introduction experiments took place during the nuptial flight period, in the second week of July 2008. We sampled the recipient workers from the 13 monogyne and eight polygyne field colonies that were previously used as sources of queens. Each field colony supplied on

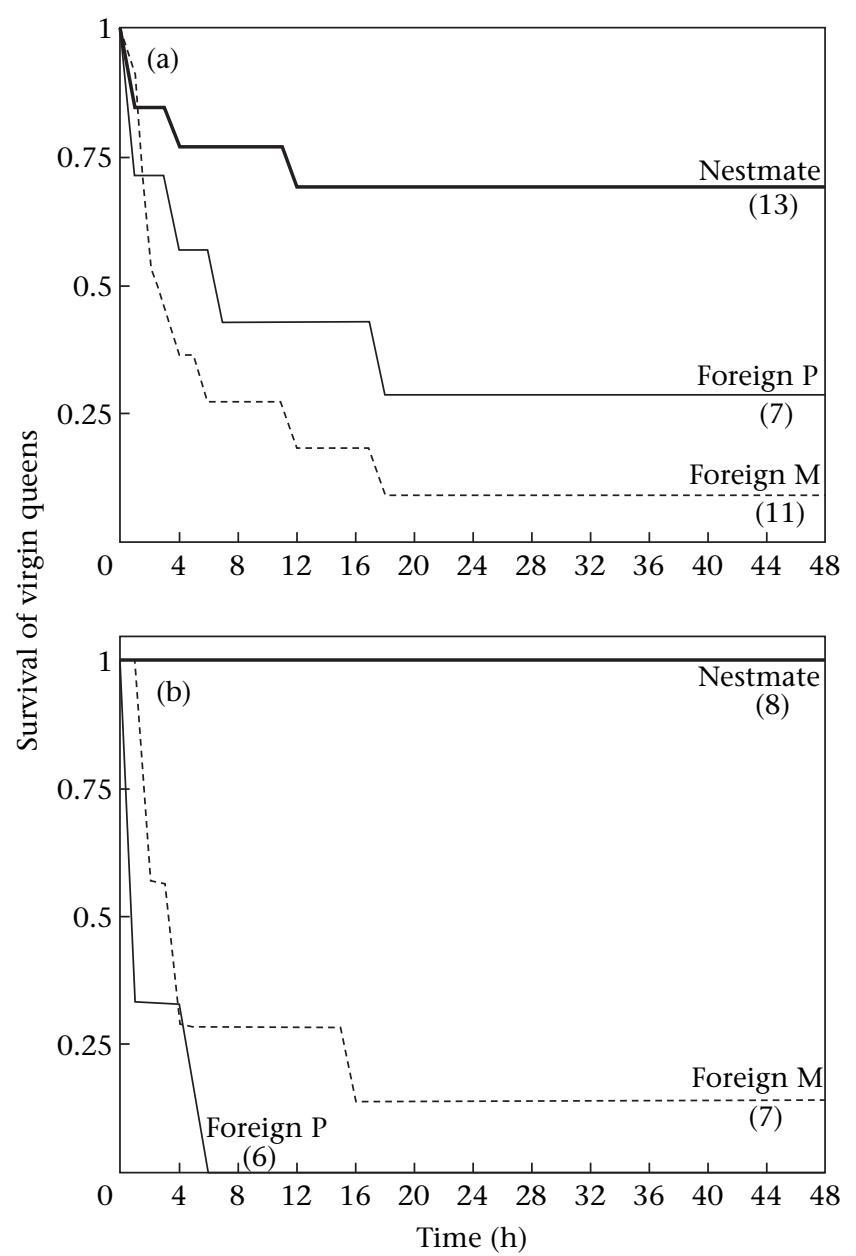

Figure 2. Cumulative survival of virgin queens introduced into groups of workers originating from (a) monogyne colonies or (b) polygyne colonies. Queens came from nestmate colonies (Nestmate), non-nestmate monogyne colonies (Foreign $\mathrm{M}$ ) or non-nestmate polygyne colonies (Foreign P). The number of recipient colonies is indicated in parentheses.

average \pm SD $6.0 \pm 2.7$ recipient groups of workers and $5.9 \pm 0.8$ introduced queens, so that at most one queen and one recipient group per colony were used in each type of assay. In total, we established 101 recipient groups of 50 workers in small plastic boxes lined with fluon (see Figs 1, 2 for sample sizes). The ants had access to food and water provided ad libitum (Meunier \& Chapuisat 2009).

Recipient groups of workers received either one mated queen or one virgin queen originating from (1) their own colony, (2) a foreign colony with the same social structure or (3) a foreign colony with the alternative social structure (Figs 1,2). The survival of introduced queens was then monitored for $48 \mathrm{~h}$. Immediately after introduction and for the next $48 \mathrm{~h}$, we recorded whether the queens were dead, alive but attacked by workers or alive and not attacked by workers. We considered that queens were attacked when, at the time of observation, at least one worker was biting one leg or one antenna of the queen. We then calculated the mean level of harassment towards queens by dividing the total number of observations during which queens were attacked by the total number of observations we made until queen death (or by 48 when the queens were still alive at the end of the experiment).

We evaluated the survival of queens with parametric survival regression models based on exponential hazard distribution and allowing for censored data (queens that were still alive $48 \mathrm{~h}$ after 
Table 1

Comparison between the survival of nestmate and non-nestmate queens (originating from monogyne or polygyne colonies) when the queens were introduced into groups of workers originating from monogyne or polygyne colonies, respectively

\begin{tabular}{|c|c|c|c|c|c|c|}
\hline & \multicolumn{3}{|c|}{$\begin{array}{l}\text { Workers from } \\
\text { monogyne } \\
\text { colonies }\end{array}$} & \multicolumn{3}{|c|}{$\begin{array}{l}\text { Workers from } \\
\text { polygyne } \\
\text { colonies }\end{array}$} \\
\hline & & $\mathrm{LR} \chi^{2}$ & $P$ & $d f$ & $f \mathrm{LR} \chi^{2}$ & $P$ \\
\hline \multicolumn{7}{|c|}{ Nestmate queens vs non-nestmate monogyne queens } \\
\hline Queen origin (nestmate vs non-nestmate) & 1 & 44.87 & $<0.001$ & 1 & 28.65 & $<0.001$ \\
\hline Mating status & 1 & 6.81 & 0.009 & 1 & 2.91 & 0.088 \\
\hline \multicolumn{7}{|c|}{ Nestmate queens vs non-nestmate polygyne queens } \\
\hline Queen origin (nestmate vs non-nestmate) & 1 & 15.08 & $<0.001$ & 1 & 34.27 & $<0.001$ \\
\hline Mating status & 1 & 4.38 & 0.036 & 1 & 0.02 & 0.900 \\
\hline
\end{tabular}

LR: likelihood ratio.

their introductions were censored). We first compared the survival of nestmate and non-nestmate queens introduced into groups of monogyne and polygyne workers. Because foreign queens came from either the same or the alternative social structure as the recipient workers, we made four separate analyses corresponding to each of the combinations between the social origins of workers and non-nestmate queens (see Table 1). The model of this first group of analyses included two fixed factors, the origin of queens (nestmate or foreign), and their mating status (virgin or mated), as well as their interaction. The survival of nestmate queens was analysed using another model where the social origin of the recipient workers (monogyne or polygyne) and the mating status of the queens were entered as fixed factors. The survival of non-nestmate queens was analysed using a third model in which the social origin of the recipient workers (monogyne or polygyne), the social origin of foreign queens (monogyne or polygyne) and their mating status were entered as fixed factors. The significant interaction in this last analysis (see Results) was explored by further comparing the effects of the social origin of foreign queens (monogyne or polygyne) in groups of either monogyne or polygyne workers. Because several groups of workers (one per type of assay) came from the same field colonies, we included the colony of origin of workers as a random factor in all our statistical models (using the frailty argument for the survreg function of R; see Therneu et al. 2003). Nonsignificant interactions between factors were removed using step-by-step procedures and likelihood ratio tests (all removed interactions had $P$ values $>0.10$ ). All statistical analyses were conducted using the $R$ 2.9.2 software (http://www.r-project.org/).

\section{RESULTS}

Workers from both monogyne and polygyne colonies discriminated against foreign queens (Figs 1, 2; Table 1). Overall, most of the non-nestmate queens died within $48 \mathrm{~h}$ (all foreign queens: mortality rate $=91.5 \%, N=59$; mated foreign queens: mortality rate $=100 \%, N=28$; Figs 1,2 ). In sharp contrast, most of the nestmate queens did survive the reintroduction (all nestmate queens: mortality rate $=28.6 \%, N=42$; mated nestmate queens: mortality rate $=38.1 \%, N=21$; Figs 1,2 ). The death of queens was correlated with the amount of worker aggression. The mean level of workers' harassment of queens was significantly higher for the 68 queens that died during the experiment than for the 33 that survived (mean $\pm \mathrm{SD}=0.356 \pm 0.250$ and $0.006 \pm 0.012$, respectively; Mann-Whitney test: $W=215, P<0.001)$. In addition, the queens that died suffered from significantly more attacks immediately after introduction than the queens that remained alive (33.8\% and 6.1\%, respectively; Fisher's exact test: $P=0.003$ ).

The short-term survival of foreign queens was influenced by an interaction between the social origin of workers and the social
Table 2

Factors affecting the survival of non-nestmate queens (originating from monogyne or polygyne colonies) introduced into groups of workers (originating from monogyne or polygyne colonies)

\begin{tabular}{llll}
\hline & $d f$ & LR $\chi^{2}$ & $P$ \\
\hline Social origin of non-nestmate queens & 1 & 6.11 & 0.013 \\
Social origin of workers & 1 & 0.43 & 0.510 \\
Mating status of non-nestmate queens & 1 & 8.23 & 0.004 \\
Interaction between the social origins of & 1 & 5.03 & 0.025 \\
$\quad$ non-nestmate queens and workers & & & \\
\hline
\end{tabular}

LR: likelihood ratio.

origin of queens (Table 2). Queens originating from polygyne colonies had a significantly longer mean survival time than queens originating from monogyne colonies when they were introduced into groups of workers originating from foreign monogyne colonies (on average 13.42 and $5.87 \mathrm{~h}$, respectively; likelihood ratio $\chi_{1}^{2}=5.28, P=0.022$ ). In contrast, the survival time of foreign queens originating from monogyne and polygyne colonies did not differ significantly when they were introduced into groups of workers originating from foreign polygyne colonies (on average 3.72 and $7.61 \mathrm{~h}$, respectively; likelihood ratio $\chi_{1}^{2}=0.31, P=0.58$ ).

The social origin of workers had no significant influence on the survival of nestmate queens (likelihood ratio $\chi_{1}^{2}=0.81, P=0.37$ ). Hence, workers from monogyne colonies were not less tolerant towards additional nestmate queens than workers from polygyne colonies. Overall, the survival of nestmate queens was approximately three times higher than that of non-nestmate queens (Figs 1,2). Nestmate queens had higher survival than non-nestmate queens in each of the four comparisons involving foreign queens and recipient workers originating from each social form (Figs 1, 2; Table 1).

Finally, the survival of queens was influenced by their mating status. Overall, virgin queens had higher survival than mated queens in groups of nestmate workers as well as in groups of foreign workers (nestmate: likelihood ratio $\chi_{1}^{2}=4.96, P=0.026$; non-nestmate: see Table 2; Figs 1,2). When we compared the survival of nestmate and non-nestmate queens, the effect of the mating status of queens was significant in groups of workers originating from monogyne colonies, but not in groups of workers from polygyne colonies, which might be caused by the small sample size in the latter case (Table 1 ).

\section{DISCUSSION}

In animal societies, the number of breeders per group often varies, but the behavioural mechanisms leading to this variation remain poorly understood. One of the proximate mechanisms influencing the structure of social groups is the behaviour of current group members towards potential breeders trying to join the group. Here, we examined whether changes in colony social structure were associated with variation in the acceptance rates of new queens by resident workers in a socially polymorphic ant.

We found that workers originating from monogyne and polygyne colonies aggressively rejected all non-nestmate mated queens seeking adoption into their nest, but were more tolerant towards additional queens originating from their own colony. The rejection of foreign queens contributes to maintaining the genetic integrity of the colony and limiting the erosion of relatedness associated with polygyny, which is consistent with kin selection models for the evolution of polygyny (Nonacs 1988; Pamilo 1991). It is in line with the fact that $F$. selysi workers from monogyne and polygyne colonies discriminate against foreign workers (Rosset et al. 2007) and confirms that the presence of multiple matrilines did not 
reduce the nestmate discrimination ability of workers in our study population. The total rejection of mated foreign queens in $F$. selysi contrasts with the occasional acceptance of unrelated queens by laboratory colonies of other socially polymorphic species (Evans 1996b; Souza et al. 2005; Zinck et al. 2009). It also indicates that our bioassay, which was based on the introduction of young newly mated queens in groups of freshly collected workers during the season of nuptial flight, was sensitive for detecting the discrimination ability of workers.

A somewhat surprising result of our study was that queens originating from foreign polygyne colonies survived for significantly longer than queens originating from foreign monogyne colonies when both types of queens were introduced into groups of workers from monogyne colonies. Such a short-term difference in queen survival is unlikely to affect the long-term acceptance rate of queens. Indeed, all the mated queens died during the first $48 \mathrm{~h}$ following their introduction into groups of foreign workers, so that queen acceptance in foreign colonies seems highly restricted.

The social structure (monogyne or polygyne) of colonies had no significant influence on the acceptance of additional nestmate queens by resident workers. In particular, the survival of nestmate queens was not significantly lower in groups of workers originating from monogyne colonies than in groups of workers originating from polygyne colonies. This result strongly contrasts with results obtained in S. invicta, where workers from monogyne colonies executed additional mated queens, while workers from polygyne colonies only accepted queens originating from polygyne colonies (Ross \& Keller 1998, 2002). It suggests that in our study population the two types of social structures are not primarily maintained by pronounced differences in the behaviour of workers towards queens.

The power of our experiment would have been sufficient to detect a large difference between the two social forms in the rate of queen acceptance by workers, of a magnitude similar to that documented in the fire ant (Ross \& Keller 1998, 2002). However, small differences in the rate of queen acceptance may have remained undetected, and may still help explain social structure variation if queen life span is long and the number of queens per colony is low. It is also possible that the long-term acceptance rate of additional queens in the field differs from that measured in our assay. For example, workers of the Argentine ant, Linepithema humile, accept many additional queens during the reproductive season but execute $90 \%$ of them within the next year (Keller et al. 1989).

The similar pattern of queen acceptance in both social forms suggests that the multiple traits that covary with changes in the social structure of the recipient colony (e.g. kin structure, body size of colony members, Chapuisat et al. 2004; Rosset \& Chapuisat 2007; Meunier \& Chapuisat 2009) had no major impact on the ability or incentive of workers to accept or reject additional queens. Moreover, the fact that workers from monogyne colonies may accept additional nestmate queens suggests that monogyne colonies might become polygynous over time. Secondary polygyny, in which an additional queen is accepted, and serial polygyny, in which the resident queen dies and is replaced by a new one, have been occasionally documented in ants (Heinze \& Keller 2000; André et al. 2001; Sanetra \& Crozier 2001; Souza et al. 2005). Our longterm genetic monitoring of colonies will reveal whether shifts in social structure occasionally occur in our study population.

The rate of acceptance of additional nestmate queens may also depend on the mating system of the species and sex ratio of the colony. Our observations in the field and mating experiments in controlled conditions suggest that intranidal mating is unlikely in F. selysi. We have regularly observed young queens flying away from their natal nests and joining nuptial flights around pine trees, as well as dealated queens walking on the ground or being attacked by workers at the nest entrance. More importantly, we have tested various experimental conditions for mating and found that mating occurs only in warm conditions under direct sunlight and immediately after the males and females have flown (Meunier et al. 2010; Reber et al. 2010). Moreover, monogyne colonies of $F$. selysi usually specialize in the production of one sex, which makes intranidal mating less likely and restricts the possibility of accepting nestmate queens into a subset of nests (Rosset \& Chapuisat 2006). It is thus possible that monogyne colonies are maintained because the virgin queens disperse before mating and rarely fly back to their nests, as has been proposed for F. truncorum (Sundström 1997).

Queens introduced into groups of monogyne and polygyne workers had higher survival when they were virgin than when they had mated. A higher survival rate of virgin queens has also been described in F. truncorum (Sundström 1997) and F. paralugubris (Fortelius et al. 1993; Holzer et al. 2008b). It probably results from reduced aggression of resident workers, which might have evolved to prevent colonies from rejecting nestmate queens before sexual maturity (see also Holzer et al. 2008b). The discrimination between virgin and mated queens could be based on changes in the composition of their cuticular hydrocarbon profiles, which are commonly used for recognition in ants. For instance, the proportion of undecane in Dufour glands of $F$. polyctena queens drops from $74 \%$ in virgins to $1 \%$ in mated queens (Lofqvist \& Bergstrom 1980). Similarly, the cuticular hydrocarbon profiles changed quantitatively as well as qualitatively once $L$. humile queens started to lay eggs (de Biseau et al. 2004). Alternatively, the discrimination between virgin and mated queens may result from changes in queen behaviour after mating.

In conclusion, our results indicate that the maintenance of monogyne and polygyne colonies in sympatry is unlikely to result from strong differences between the two types of colonies in their rate of acceptance of new queens. Workers from both social forms did not tolerate the presence of mated queens originating from foreign colonies, but tended to accept additional nestmate queens, particularly virgin ones. The elimination of non-nestmate queens by resident workers suggests that gene flow between social forms is unlikely to be maintained by queen acceptance. Hence, the lack of genetic differentiation between social forms probably results from mating between individuals of alternative social forms or from flexible colony founding by newly produced queens, as documented in a recent study of the same population (Reber et al. 2010). These results highlight how behavioural experiments can complement genetic studies and help to draw a more comprehensive picture of the mechanisms contributing to the maintenance of alternative social structures in insects.

\section{Acknowledgments}

We thank Mathias Koelliker, Jessica Purcell and two anonymous referees for comments on the manuscript, as well as Timothée Brutsch and Luma Delaplace for help in the field and in the laboratory. This study was supported by the Swiss National Science Foundation (Grants no. 31003A-108263 and 31003A-125306).

\section{References}

André, J. B., Peeters, C. \& Doums, C. 2001. Serial polygyny and colony genetic structure in the monogynous queenless ant Diacamma cyaneiventre. Behavioral Ecology and Sociobiology, 50, 72-80.

Bargum, K., Helanterä, H. \& Sundström, L. 2007. Genetic population structure, queen supersedure and social polymorphism in a social Hymenoptera. Journal of Evolutionary Biology, 20, 1351-1360.

Bennett, B. 1988. Discrimination of nestmate and non-nestmate sexuals by ants (Hymenoptera: Formicidae). Insectes Sociaux, 35, 82-91.

de Biseau, J. C., Passera, L., Daloze, D. \& Aron, S. 2004. Ovarian activity correlates with extreme changes in cuticular hydrocarbon profile in the highly polygynous ant, Linepithema humile. Journal of Insect Physiology, 50, 585-593. 
Bourke, A. F. G. \& Franks, N. R. 1995. Social Evolution in Ants. Princeton, New Jersey: Princeton University Press.

Breed, M. D. \& Bennett, B. 1987. Kin recognition in highly eusocial insects. In: Kin Recognition in Animals (Ed. by D. J. C. Fletcher \& C. D. Michener), pp. 243-285. Chichester: J. Wiley.

Chapuisat, M. \& Keller, L. 1999. Extended family structure in the ant Formica paralugubris: the role of the breeding system. Behavioral Ecology and Sociobiology, 46, 405-412.

Chapuisat, M., Bocherens, S. \& Rosset, H. 2004. Variable queen number in ant colonies: no impact on queen turnover, inbreeding, and population genetic differentiation in the ant Formica selysi. Evolution, 58, 1064-1072.

Cournault, L. \& de Biseau, J. C. 2009. Hierarchical perception of fertility signals and nestmate recognition cues in two dolichoderine ants. Behavioral Ecology and Sociobiology, 63, 1635-1641.

Crozier, R. H. \& Pamilo, P. 1996. Evolution of Social Insect Colonies: Sex Allocation and Kin Selection. Oxford: Oxford University Press.

Deslippe, R. J. \& Savolainen, R. 1995. Colony foundation and polygyny in the ant Formica podzolica. Behavioral Ecology and Sociobiology, 37, 1-6.

Emlen, S. T. 1997. Predicting family dynamics in social vertebrates. In: Behavioura Ecology: an Evolutionary Approach (Ed. by J. R. Krebs \& N. B. Davies), pp. 228-253. Oxford: Blackwell Science.

Evans, J. D. 1996a. Competition and relatedness between queens of the facultatively polygynous ant Myrmica tahoensis. Animal Behaviour, 51, 831-840.

Evans, J. D. 1996b. Queen longevity, queen adoption, and posthumous indirect fitness in the facultatively polygynous ant Myrmica tahoensis. Behavioral Ecology and Sociobiology, 39, 275-284.

Fortelius, W., Rosengren, R., Cherix, D. \& Chautems, D. 1993. Queen recruitment in a highly polygynous supercolony of Formica lugubris (Hymenoptera, Formicidae). Oikos, 67, 193-200.

Hamilton, W. D. 1964. The genetical evolution of social behaviour. Journal of Theoretical Biology, 7, 1-52.

Heinze, J. \& Keller, L. 2000. Alternative reproductive strategies: a queen perspective in ants. Trends in Ecology \& Evolution, 15, 508-512.

Hölldobler, B. \& Wilson, E. O. 1977. The number of queens: an important trait in ant evolution. Naturwissenschaften, 64, 8-15.

Hölldobler, B. \& Wilson, E. O. 1990. The Ants. Berlin: Springer-Verlag.

Holzer, B., Chapuisat, M. \& Keller, L. 2008a. Foreign ant queens are accepted but produce fewer offspring. Oecologia, 157, 717-723.

Holzer, B., Meunier, J., Keller, L. \& Chapuisat, M. 2008b. Stay or drift? Queen acceptance in the ant Formica paralugubris. Insectes Sociaux, 55, 392-396.

Holzer, B., Keller, L. \& Chapuisat, M. 2009. Genetic clusters and sex-biased gene flow in a unicolonial Formica ant. BMC Evolutionary Biology, 9, 69.

Hora, R. R., Ionescu-Hirsh, A., Simon, T., Delabie, J., Robert, J., Fresneau, D. \& Hefetz, A. 2008. Postmating changes in cuticular chemistry and visual appearance in Ectatomma tuberculatum queens (Formicidae: Ectatomminae). Naturwissenschaften, 95, 55-60.

Hughes, W. O. H., Oldroyd, B. P., Beekman, M. \& Ratnieks, F. L. W. 2008a Ancestral monogamy shows kin selection is key to the evolution of eusociality. Science, 320, 1213-1216.

Hughes, W. O. H., Ratnieks, F. L. W. \& Oldroyd, B. P. 2008b. Multiple paternity or multiple queens: two routes to greater intracolonial genetic diversity in the eusocial Hymenoptera. Journal of Evolutionary Biology, 21, 1090-1095.

Jennions, M. D. \& Macdonald, D. W. 1994. Cooperative breeding in mammals Trends in Ecology \& Evolution, 9, 89-93.

Keller, L. 1995. Social life: the paradox of multiple-queen colonies. Trends in Ecology E Evolution, 10, 355-360.

Keller, L. \& Reeve, H. K. 1994. Genetic variability, queen number, and polyandry in social hymenoptera. Evolution, 48, 694-704.

Keller, L., Passera, L. \& Suzzoni, J. P. 1989. Queen execution in the Argentine ant Iridomyrmex humilis (Mayr). Physiological Entomology, 14, 157-163.

Kikuchi, T., Tsuji, K., Ohnishi, H. \& Le Breton, J. 2007. Caste-biased acceptance of non-nestmates in a polygynous ponerine ant. Animal Behaviour, 73 $559-565$
Lofqvist, J. \& Bergstrom, G. 1980. Volatile communication substances in Dufours gland of virgin females and old queens of the ant Formica polyctena. Journal of Chemical Ecology, 6, 309-320.

Meunier, J. \& Chapuisat, M. 2009. The determinants of queen size in a socially polymorphic ant. Journal of Evolutionary Biology, 22, 1906-1913.

Meunier, J., Delaplace, L. \& Chapuisat, M. 2010. Reproductive conflicts and egg discrimination in a socially polymorphic ant. Behavioral Ecology and Sociobiology, 64, 1655-1663, doi:10.1007/s00265-010-0979-z.

Nonacs, P. 1988. Queen number in colonies of social Hymenoptera as a kin-selected adaptation. Evolution, 42, 566-580.

Pamilo, P. 1991. Evolution of colony characteristics in social insects. II. Number of reproductive individuals. American Naturalist, 138, 412-433.

Reber, A., Castella, G., Christe, P. \& Chapuisat, M. 2008. Experimentally increased group diversity improves disease resistance in an ant species. Ecology Letters, 11, 682-689.

Reber, A., Meunier, J. \& Chapuisat, M. 2010. Flexible colony-founding strategies in a socially polymorphic ant. Animal Behaviour, 78, 467-472.

Rosengren, R., Cherix, D. \& Pamilo, P. 1986. Insular ecology of the red wood ant Formica truncorum: II. Distribution, reproductive strategy and competition. Mitteilungen der Schweizerischen Entomologischen Gesellschaft, 59, 63-93.

Ross, K. G. \& Keller, L. 1995. Ecology and evolution of social organization: insights from fire ants and other highly eusocial insects. Annual Review of Ecology and Systematics, 26, 631-656.

Ross, K. G. \& Keller, L. 1998. Genetic control of social organization in an ant Proceedings of the National Academy of Sciences, U.S.A., 95, 14232-14237.

Ross, K. G. \& Keller, L. 2002. Experimental conversion of colony social organization by manipulation of worker genotype composition in fire ants (Solenopsis invicta). Behavioral Ecology and Sociobiology, 51, 287-295.

Rosset, H. \& Chapuisat, M. 2006. Sex allocation conflict in ants: when the queen rules. Current Biology, 16, 328-331.

Rosset, H. \& Chapuisat, M. 2007. Alternative life-histories in a socially polymorphic ant. Evolutionary Ecology, 21, 577-588.

Rosset, H., Schwander, T. \& Chapuisat, M. 2007. Nestmate recognition and levels of aggression are not altered by changes in genetic diversity in a socially polymorphic ant. Animal Behaviour, 74, 951-956.

Sanetra, M. \& Crozier, R. H. 2001. Polyandry and colony genetic structure in the primitive ant Nothomyrmecia macrops. Journal of Evolutionary Biology, 14 368-378.

Sherman, P. W., Lacey, E. A., Reeve, H. K. \& Keller, L. 1995. The eusociality continuum. Behavioral Ecology, 6, 102-108.

Souza, D. J., Della Lucia, T. M. C. \& Lima, E. R. 2005. Queen adoption in colonies of the leaf-cutting ant Acromyrmex subterraneus molestans (Hymenoptera: Formicidae). Behavioural Processes, 70, 62-68.

Stuart, R., Gresham-Bisset, L. \& Alloway, T. 1993. Queen adoption in the polygynous and polydomous ant, Leptothorax curvispinosus. Behavioral Ecology, 4, 276-281.

Sundström, L. 1997. Queen acceptance and nestmate recognition in monogyne and polygyne colonies of the ant Formica truncorum. Animal Behaviour, 53, 499-510.

Szathmary, E. \& Maynard Smith, J. 1995. The major evolutionary transitions Nature, 374, 227-231.

Therneu, T., Grambsch, P. \& Pankratz, V. 2003. Penalized survival models and frailty. Journal of Computational and Graphical Statistics, 12, 156-175.

Vander Meer, R. K. \& Morel, L. 1998. Nestmate recognition in ants. In: Pheromone Communication in Social Insects (Ed. by R. K. Vander Meer, M. Breed, M. Winston \& K. E. Espelie), pp. 79-103. Boulder, Colorado: Westview.

Vasquez, G. M. \& Silverman, J. 2008. Queen acceptance and the complexity of nestmate discrimination in the Argentine ant. Behavioral Ecology and Sociobiology, 62, 537-548.

Wilson, E. O. 1971. The Insect Societies. Cambridge, Massachusetts: Harvard University Press.

Zinck, L., Denis, D., Hora, R. R., Alaux, C., Lenoir, A., Hefetz, A. \& Jaisson, P. 2009 Behavioral and chemical correlates of long-term queen adoption in the facultative polygynous ant Ectatomma tuberculatum. Journal of Insect Behavior, 22 $362-374$ 